\title{
Moulded Pulp Manufacturing: Overview and Prospects for the Process Technology
}

Didone, Mattia; Saxena, Prateek; Meijer, Ellen Brilhuis; Tosello, Guido; Bissacco, Giuliano; McAloone, Tim C.; Pigosso, Daniela Cristina Antelmi; Howard, Thomas J.

Published in:

Packaging Technology and Science

Link to article, DOI:

$10.1002 /$ pts.2289

Publication date:

2017

Document Version

Peer reviewed version

Link back to DTU Orbit

Citation (APA):

Didone, M., Saxena, P., Meijer, E. B., Tosello, G., Bissacco, G., McAloone, T. C., Pigosso, D. C. A., \& Howard, T. J. (2017). Moulded Pulp Manufacturing: Overview and Prospects for the Process Technology. Packaging Technology and Science, 30(6), 231-249. https://doi.org/10.1002/pts.2289

\section{General rights}

Copyright and moral rights for the publications made accessible in the public portal are retained by the authors and/or other copyright owners and it is a condition of accessing publications that users recognise and abide by the legal requirements associated with these rights.

- Users may download and print one copy of any publication from the public portal for the purpose of private study or research.

- You may not further distribute the material or use it for any profit-making activity or commercial gain

- You may freely distribute the URL identifying the publication in the public portal 


\title{
Molded Pulp Manufacturing: Overview and Prospects for the Process Technology
}

\author{
Mattia Didone, Prateek Saxena, Ellen Brilhuis-Meijer, Guido Tosello, Giuliano Bissacco,
} Tim C. McAloone, Daniela Cristina Antelmi Pigosso, Thomas J. Howard

Technical University of Denmark, Department of Mechanical Engineering, 2800 Kgs. Lyngby, Denmark

\begin{abstract}
Eco-friendly packaging such as molded pulp products have gained commercial importance in recent years. However, it remains a greatly under-researched area and there is an arising need to consolidate the best practices from research and industry in order to increase its implementation. The goal of this paper is to give an overview of the main aspects involved in the manufacture of molded pulp products. This includes a classification of molded pulp products, historical and current applications, production processes, materials, mechanical properties, and environmental sustainability. Moreover, based on the latest research in the field, an innovative drying technique that utilizes concepts derived from impulse drying is presented and the implementation of this process technology is discussed.
\end{abstract}

KEYWORDS: Molded pulp, precision molding, compression molding, thermoformed molded pulp, impulse drying, environmental sustainability 


\section{Introduction}

Molded pulp products, also referred to as molded pulp or molded fiber products, are primarily used for the packaging of manufactured products and for food-related carriers, such as food containers and serving trays.

Due to form (geometry) and aesthetic limitations, molded pulp products have mostly been limited to the egg tray market for many years. However, demand is now increasing due to their sustainable qualities [1]. Environmental, social, and economic concerns result in a growing search for more sustainable products and industrial processes. As it consists simply of water and wood fibers (i.e. primarily cellulose), molded pulp is a renewable material and a biodegradable solution. The manufacturing process includes the recovery of discarded materials from manufactured and recycled products made of wood fibers, such as cardboard, newspapers, magazines, etc. These qualities have enabled growing adoption within the packaging industry. Companies are eager to embrace alternatives to oil-based forms of packaging, due to government regulations and customer demands [2]. Increasing $R \& D$ effort for standardizing design and testing practices is essential in order to meet the growing demand for eco-packaging with high quality features.

Reviews of the historical development in industrial applications of molded pulp packaging, recent manufacturing innovations in the field, and an overview of an industrial scenario in the UK are discussed respectively in [1], [3], [4]. Fundamentals of the technology for manufacturing molded pulp, which date back to 1966, are also discussed by Emery and Emery [5]. While these articles give great insight into historical developments, they are outdated and they report few of the recent innovations within the field. Consequently, not enough attention has been given to the different manufacturing processes and there is a gap related to environmental considerations. By means of a comprehensive review, this paper fills the identified research gap by describing wide-ranging aspects of the manufacturing process of molded pulp. The research method adopted in collecting and reviewing the publications focused the literature survey exclusively to molded pulp. It excluded similar products used in the packaging industry, such as cardboard or honeycomb panels.

The content has been organized to present the main aspects involved in the manufacturing of molded pulp products: the process, the materials, the mechanical properties, and their environmental sustainability. In addition, a novel idea that exploits the concept of impulse drying is introduced and discussed. The information presented in this paper is essential to understand the overall capabilities and limitations of molded pulp products. It will serve as a starting point for designers, engineers, and scientists to conduct in-depth studies for application-specific requirements. The introduction covers the classification of products, the historical development and the most recent innovations (Section 1). Section 2 discusses the two different manufacturing processes, plain and precision molding, and the available tooling technologies. In Section 3, the potential application of the impulse drying concept for the process technology is presented. The latest research on the materials employed in the production of molded pulp and their mechanical properties are presented in Section 4 and Section 5, respectively. Finally, Section 6 gives some environmental considerations about the molded pulp sustainability. 


\subsection{Classification of molded pulp products}

Molded pulp describes a three-dimensional package that has been classified in numerous different ways over the years. The basis of the classification used to be based on the product density, production process, and fabrication method [6]. However, as per the guidelines from the International Molded Fiber Association (IMFA) [7] they can now be categorized as follows:

1. Thick wall: manufactured using an open mold and then oven dried. Typical wall thickness ranges from $5 \mathrm{~mm}$ to $10 \mathrm{~mm}$. The surface in contact with the mold is relatively smooth, while the other side is very rough. The raw material is typically Kraft paper mixed with recycled paper. The typical application is support packaging for non-fragile and heavy items (e.g. furniture and vehicle parts).

2. Transfer molded: products in this category have thinner walls, $3 \mathrm{~mm}$ to $5 \mathrm{~mm}$. They are manufactured using both a forming mold and a transfer or take-off mold. The result is a product with relatively smooth surfaces on both sides and better dimensional accuracy. The formed product is dried in a heated oven. The raw material commonly used is recycled newspaper [8]. Typical examples are egg trays and packaging for electronic equipment.

3. Thermoformed (thin-wall): this is the most recent manufacturing approach. The initial, partially formed product is captured in a heated mold where it is pressed, densified and dried. No oven curing is needed. The process produces high quality, thin-walled items (from $2 \mathrm{~mm}$ to $4 \mathrm{~mm}$ ), with good dimensional accuracy, and smooth rigid surfaces. The result resembles the appearance of thermoformed plastic items.

4. Processed: this refers to molded pulp products that require further or special treatments, for instance additional printing, coatings, or additives.

The classification brings greatly needed clarity, since publications on this topic often do not distinguish between the types of molded pulp processes.

\subsection{History and applications}

In the mid-1800s, with the mass distribution of newspapers and books, the prices for paperrelated products dropped, and thus new applications emerged. The first appearance of a method for making molded products from wood pulp dates back to 1890 [9]. The first patent for a machine for making pulp products was registered in 1903 by Martin L. Keyes, from Cambridge, Massachusetts [10]. Within a year, he registered another patent with a structural improvement to the machinery [11]. Molded pulp was soon after used as packaging for eggs, which was designed and produced by the Canadian inventor Joseph Coyle. However, the production machinery was not developed until after the First World War. The shape of the package could be easily varied. Consequently, the invention was applied to all sorts of fragile items, including light bulbs and fruit. The patent for such a multi-use package was registered in 1920 [12]. Since then, the implementation of molded pulp products slowly increased, and 
examples of other patented applications include a folding spoon for medicine, a pastry holder, and a packaging for a handset telephone (1940) [13].

In modern times, molded pulp is primarily associated with egg packaging, fruit trays, and drink carriers; however, there are many other applications such as food containers, clinical healthcare products, and packaging for electronic goods. In general, these products are related to three kinds of markets: food related products, industrial packaging, and disposable items. Molded pulp is also used as a cushioning material for the protection of a product during transportation, e.g. molded honeycomb paperboard. With its high strength, durability, and low cost, this material can be a replacement for wood and plastics [14].

\subsection{New trends and recent innovations}

Starting from the late 1980s, consumers started to develop an interest in the environmental impact of the products that they were buying. Tetra Pak ${ }^{\odot}$ recently released a report [15] showing that buyers are seeking sustainable packaging to the extent that it affects their choice of brands. This suggests that sustainable packaging is not just for the sake of the environment, but also necessary for the sustainability of the brand.

The report Packaging 2020 [16] portrays the likely market scenario for 2020 for consumer packaging. It states that, as the world continues to urbanize, demand for packaging is likely to grow rapidly with a consequent need to develop efficient recycling systems. Lifestyles trend towards convenience, health, and environmental awareness will grow in importance for consumers. Not only has the public opinion become more sensitive to the subject, but also national and international legislation has become more stringent. For instance, China and Taiwan banned the use of Styrofoam containers in 1999. Products in the form of dishes, soup bowls, lunch boxes, and various fast food containers had to be replaced with more sustainable alternatives, such as molded paper [17].

Another initiative is the Forest Fiber Industry 2050 Roadmap to a low-carbon economy [18]. The Roadmap represents the vision for the sector with the assumption that consumers in the future will prefer sustainable bio-based goods to other materials.

In recent years, several companies have come forward to create environmentally sustainable products often involving extensive use of recycled paper. For example, Seventh Generation $^{\mathrm{TM}}$ has launched a new laundry-detergent bottle that uses molded pulp for the structural part of the container, while the detergent itself is contained in a plastic lining. In this way, the use of plastic is reduced by more than half [19]. Pangea Organics ${ }^{\circledR}$ packages soap in a clamshell made out of processed pulp which has plant seeds embedded in the packaging for planting on disposal [3]. Paper Water Bottle ${ }^{\circledR}$ (Figure 1) has prototyped an eco-friendly replacement for plastic water/beverage bottles with a shell made entirely of renewable molded fiber and an internal barrier that requires less plastic than a standard plastic bottle [20]. 


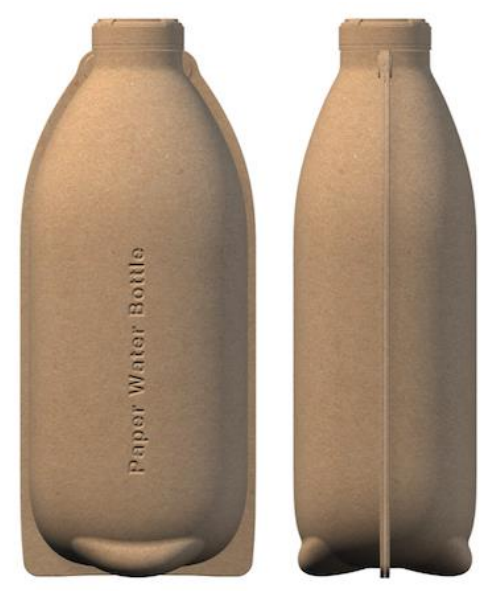

Figure 1: Paper Water Bottle ${ }^{\circledR}$ product rendering [20]

The Green Fiber Bottle project [21], [22] aims to go one better by making a fully molded paper bottle removing the need for an inner liner and making the bottle completely biodegradable. A consortium of industrial and academic partners are collaborating with Carlsberg A/S, who aims to package its beer in the new bottle. A prototype of the paper bottle can be seen in Figure 2 .

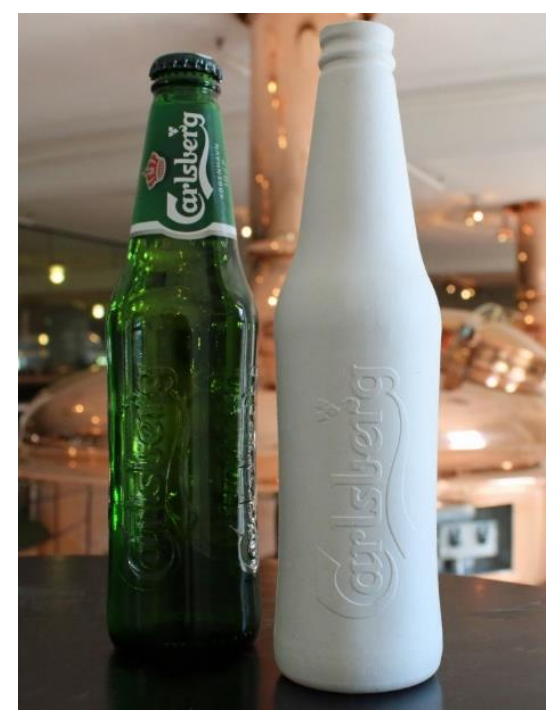

Figure 2: Green Fiber Bottle prototype [21] 


\section{Manufacturing processes}

Most of the packaging products, such as Tetra Pak ${ }^{\odot}$ cartons, start with the manufacturing of flat sheets which are then assembled into three-dimensional packages. Production of molded pulp involves a series of manufacturing steps. The process is tailored to the geometry and usage of the final product. There are two main steps involved in the manufacturing process: vacuum-forming of the pulp into the desired shape and drying the product to remove the remains of the water [4]. During the forming process, water is removed by the vacuum, the solid content in the formed product is in the range of about $40 \%$ to $55 \%$. The remaining water content is removed in the drying step. The finished product thus have a moisture content of about $4 \%$ to $8 \%$, roughly corresponding to the equilibrium moisture content of the paper under the humidity conditions at which it will be stored or used [23].

The development of a tooling solution for the manufacturing of molded products depends essentially on the targeted use of the packaging product. The tool design depends on whether a smooth surface generation is a desirable feature on the inner or the outer surface of the packaging product, due to secondary operations such as coating, labelling etc. For the purpose of product the mold tool should be designed in order to:

- replicate the desired geometry of the final product,

- produce desired surface finish quality,

- sustain a large number of stress cycles,

- allows cleaning between production cycles, and

- be resistant to corrosion and inert towards the pulp slurry.

The first tool setup developed by Keyes [10] consisted of two separate mold halves. One half of the mold is dipped in the fiber suspension; the two halves are then matched and the pulp is pressed. Excess water is drained out by vacuum-assisted compaction. Once the molded product is formed between the two halves of the tool, it is then transferred to an oven and dried.

Forming and drying of paper pulp is discussed in detail in the subsequent sections.

\subsection{Forming process}

In the forming process, the dies are immersed in a tank filled with pulp (stock pond) where the pulp is sucked onto the mold, via a vacuum-assisted process. The pulp consists mainly of water, short fibers and fines. The materials are blended with hot water for about 20 min until they become pulp. In case of recycled materials, such as cardboards, newspapers, magazines, recycled papers, and other paper-based products, the pulp goes through a set of vibrating screens that remove impurities like plastics and metals.

The custom designed die, which is the negative of the geometry to be formed, is attached to the molding machine. The combination of dies attached to the molding machine is called the molding pattern. The die is immersed in the stock pond and through vacuum suction the pulp is deposited on the outer surface of the die. The pulp accumulates to a desired thickness and the mechanically bound water is removed via a vacuum-assisted process. 
The deposition of the wet-pulp on the forming tool is a form of wet pressing. Cellulose fibers in the wet-pulp are entangled in a way that they make the entire structure porous. During pressing, two types of stress are generated: stress due to the fiber structure, which provides resistance to the flow of water in the web, and stress due to the hydraulic pressure. Terzaghi's principle [24], which is a phenomenon usually referred to in soil mechanics, states that the total stress anywhere in a porous medium is constant and is equal to the sum of the two stresses just discussed. Campbell [25] was the first to apply this concept to paper forming, thereby verifying and quantifying the behavior of the wet web during the formation of paper. Stress applied during pressing gets counter balanced by the two stresses and the hydraulic pressure squeezes the water outwards.

Wet pressing process is influenced by the compressibility of the fiber network. Several researchers have studied the deformation of wet webs using a platen press [26]-[28]. In these studies, the paper web was compressed in-between a smooth solid material and a rough porous material. The expelled water was taken up by the porous material and transferred outwards by the drainage channels as shown in Figure 3.

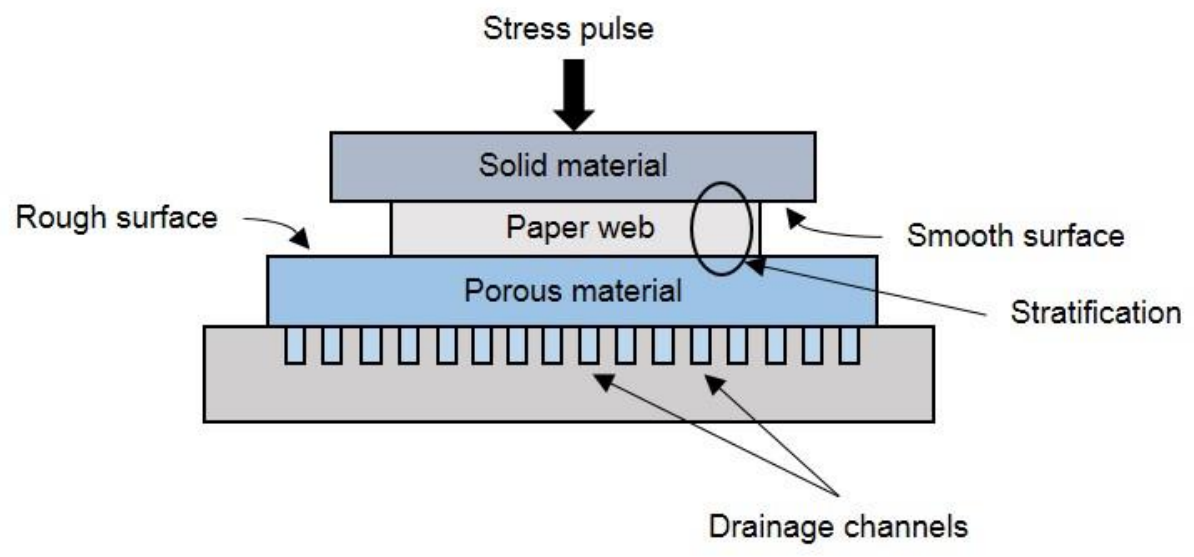

Figure 3: Study of the deformation of wet webs during wet pressing by using a platen press

In the platen press arrangement, water flows through the fiber network and experiences viscous forces. The interaction results in a non-uniform and uneven compaction of the wet web in the thickness direction. This phenomenon is termed as stratification [29], [30].

During compression, water is not only squeezed out of the fiber network but also through the fiber walls. Vomhoff and Norman [31] indicated that the pressure should be directed towards the fiber and must be uniform throughout to avoid uneven surfaces.

The agglomeration of pulp fibers in the passageways of the forming tool could obstruct the water flow. To prevent the problem, the tool must be cleaned at each production cycle. Goto and Keiji [32] developed a forming tool that allows the feeding of purging fluid for cleaning the papermaking screen.

\subsection{Drying process}

Once the product is formed, it is then removed from the forming tool and transferred for the subsequent drying process. Two fundamental methods of drying can be identified: plain and 
precision molding. The forming process is the same for both methods. For plain molding oven drying is preferred, while in precision molding heat is applied between the matching mold surfaces [33].

Plain molding involves drying of the formed products in a heated oven. Figure 4 shows the process chain of the plain molding process. Products of plain molding fall in the thick wall and the transfer molded categories. Production systems for such products are usually designed for large volume production with high levels of automation. The amount produced is typically greater than 20 tons per day ( $>18$ metric tons per day), and it depends on the molding patterns and speed of the molding machine. Secondary treatments, such as printing, coating etc., are sometimes given. Colored molded packaging are obtain using a dyed pulp. Decorative finishes can be realized by spray gun [33], [34].

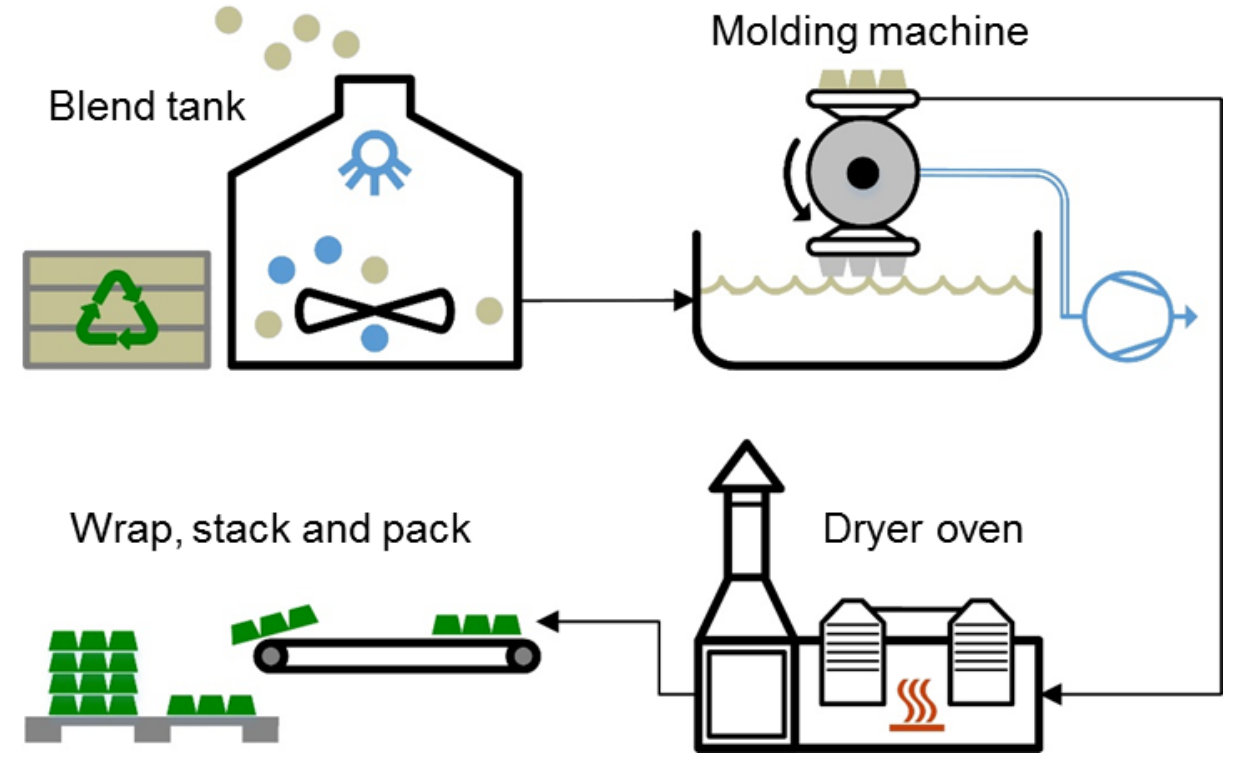

Figure 4: Process chain of the plain molding process

The drying process in the precision molding process (Figure 5) is performed by applying heat in between the surfaces of a matching mold. This manufacturing process is also referred to as compression molding or thermoforming process. During the drying process, the part is pressed, making the products denser, smoother, and more precise than their freedried counterparts. The pressing also increases the bonding between the fibers, thus improving the mechanical properties. Virtually any plain-molded product can be made in this manner, but the product cost and electrical energy input would increase. This is the reason why the production is tailored for high quality and more valuable products but in smaller volumes. 


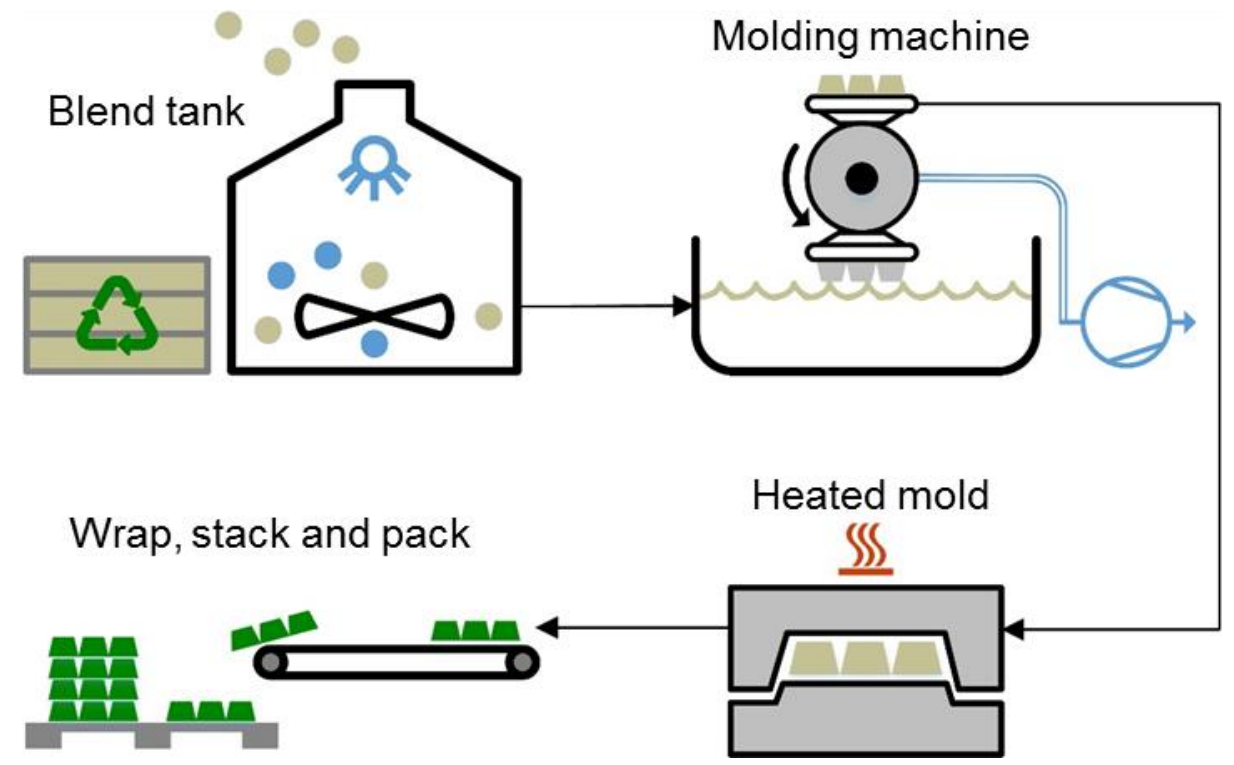

Figure 5: Process chain of the precision molding process

Products of this manufacturing process belong to the thermoformed category that includes plates, bowls, dishes and specialty products such as loudspeaker membranes and cones [33]. Secondary treatments are not usually needed.

In a recent advancement in precision molding (2016), Søllner [35] suggested a system and a method for producing molded products by lowering the energy consumption, production time and/or production costs. The formed product is transferred from the forming to the drying tool by means of a rotating table. The articles are pressed from inside during drying, thus avoiding any expansion of paper. Water in the form of steam is evacuated through a porous mold by vacuum-suction. 


\section{Prospects for the process technology}

Production of molded pulp is an energy intensive operation. Just as in the conventional papermaking process, a large portion of resources (in terms of time and energy) is consumed in the drying process. In this process stage, an innovative way of drying the products based on the concept of impulse drying can be exploited. The potential of this technology can be explored for the production of precision molding products, since the drying is performed in a more controlled way than their free dried counterparts.

This section summarizes the main features and operational problems of the impulse drying technology. Finally, the prospect of the introduction of such innovation in the manufacturing of molded pulp is discussed.

\subsection{Impulse drying technology}

Impulse drying is an advance drying technique in which, water is removed from a wet paper web by the combination of mechanical pressure and intense heat. It was introduced in the beginning of the 1980s by Wahren [36], and it attracted considerable interest from the paper industry as a means of reducing energy consumption in the drying process. Despite over twenty years of research, this technology has never been applied in the paper industry due to various runnability problems affecting the paper quality. Consequently, this caused the interest in this technique to wane.

In this process, the wet web is exposed to pressures ranging from 30 bar to 50 bar and to hot surface temperatures typically between $200{ }^{\circ} \mathrm{C}$ to $400{ }^{\circ} \mathrm{C}$ [37]. The dwell, or nip, residence time (i.e. the time that the paper sheet remains in the press nip) is around $20 \mathrm{~ms}$ to $50 \mathrm{~ms}$ and takes place in a so-called shoe-nip press that replaces the conventional press nip [38], see Figure 6.
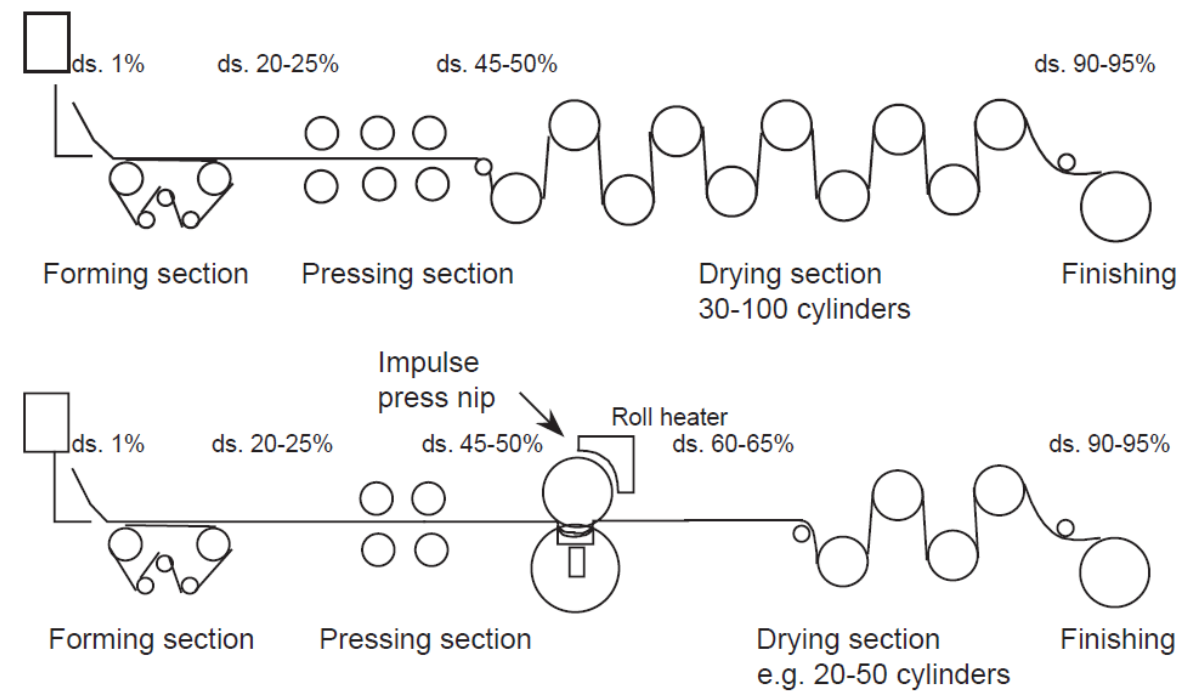

Figure 6: Conventional paper machine (top) and a machine with one impulse shoe-nip press (bottom) (ds = percentage of dry solids in paper sheet) [39] (reprinted with permission from Elsevier)

Impulse drying is similar in nature to conventional wet-pressing operations but with applied heat. The applied heat has two main roles: to reduce the viscous resistance in the fluid 
phase and to improve fiber flexibility and conformability [40]. Within the moisture and temperature ranges of impulse drying, it is predominantly the lignin that is softened while the other amorphous polymers (i.e. cellulose and hemicellulose) are always above their glass transition temperatures. Consequently, for unbleached and mechanical pulps (i.e. lignin containing pulps) the dewatering effect is more prominent in comparison to the bleached pulps [38].

Impulse drying enhances paper properties, such as tensile strength, internal cohesion, and burst resistance. The process has a high potential for promoting web consolidation and increased paper density. Therefore, product strength is improved by providing a decrease in fiber consumption and the use of low cost recycled materials [37], [38].

The mechanism of impulse drying is complex. Various phenomena interact over a very short time period, such as heat transfer, multiphase flow, sheet compressibility, and thermodynamics. It was suggested that if the heat transfer rate is sufficiently high, a vapor phase can be generated on the wet-side of the paper in contact with the high temperature medium [40]. This may assist in the dewatering process, since the expanding steam could displace the bounded water. This effect was recently studied and termed flashing-assisted displacement dewatering by Lucisano et al. [41]. However, the research activities have not yet resulted in a proven technology and its prospects in the papermaking industry are still unclear [39]. It is important that further research be conducted to clarify the complex mechanism of dewatering in impulse drying.

\subsection{Runnability problems}

The introduction of impulse drying technology in the paper industry has been hampered mainly by two runnability problems: web delamination and paper adhesion to the heated roll surface [38].

Delamination is defined as a sudden reduction of strength in the thickness direction of the paper. To prevent delamination, the fiber-to-fiber bonds must withstand the energy generated by the water, gases, or steam moving in any direction during the impulse drying process [42]. The water permeability of the paper web is thus an important factor in controlling delamination. Low basis weight paper, for instance, would facilitate the escape of flashed vapor from the sheet without the occurrence of delamination [38]. In order to prevent delamination, pressure must be maintained after opening the shoe-nip in order to allow the paper to cool down and prevent damage to the fiber-to-fiber bonds. Delamination can also be controlled by reducing the temperature within the sheet just prior to opening the nip. A reduced sheet temperature would reduce the quantity of flashed vapor formed during nip decompression. Mendes et al. [38] suggested that a press roll surface made with a porous surface allows the vapor pressure within the sheet to be relieved and reduce the amount of heat transferred to the paper web. However, these measures would result in a longer cycle time and increased investment in equipment [41]. Insufficient water removal from the impulse drying unit can also lead to the re-wetting of the paper. 


\subsection{Potential of impulse drying for manufacturing molded pulp products}

The application of the impulse drying concept for the manufacture of molded pulp products was only recently reported [43]. The processing conditions for precision molding manufacturing are characterized by the molding temperature, pressure, and process time [44]. These variables are controlled based on the composition and consistency of the pulp used and its physical properties (e.g. temperature and viscosity). As explained earlier, these are also the three main variables on which the impulse drying technology is based. These parameters must therefore be fine-tuned in order to achieve the benefits of the flashingassisted displacement dewatering effect, which occurs at a high and controlled temperature and pressure.

The technology could be applied in the production of two-dimensional products and could be extended to the production of products with a three-dimensional closed geometry, as described in several patent applications [32], [35], [45]-[49]. The patents generally describe the possibility of inserting an elastic and hollow pressing member inside the preform, as shown in Figure 7. A pressurizing fluid is then fed into the pressing member to inflate it, thereby applying pressure to the inside of the mold.

The manufacture of precision molding products could thus benefit from the introduction of impulse drying technology in terms of energy saving and reduced process time.

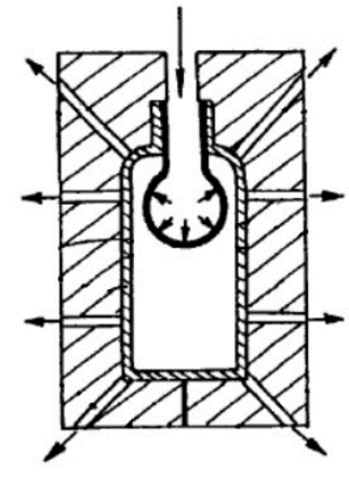

a

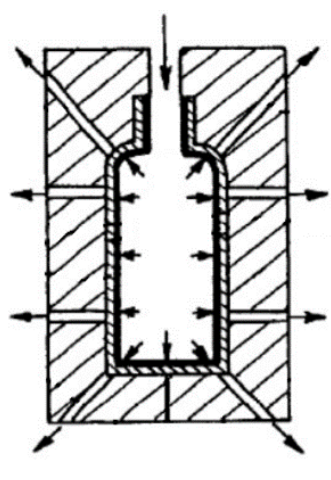

b

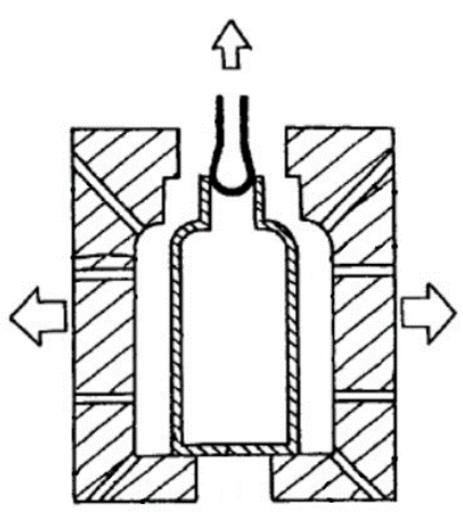

C

Figure 7: Patent application by Kumamoto et al. Cross sectional views showing the steps of: (a) inserting a hollow elastic body; (b) inflating the elastic body and pressing the hollow container onto the inner wall of a heated mold; (c) removing the elastic body and opening of the mold (modified from [46]) 


\section{Materials}

The majority of molded pulp products are prepared from cellulose fibers mixed with water, which forms the aggregate known as pulp. For the production of plain molding products, recovered paper is usually used. The reuse of waste paper, however, is limited by the ease and cost of collection and by the number of times that fibers can be recycled (up to five to seven times) [50]. Virgin fibers are usually used instead of recover paper for the manufacture of precision molded items. Many internal treatments can also be given to render them more valuable. Drainage, internal bond strength, and shrinkage can be altered by refining processes and the use of additives [33].

The pulp consistency commonly ranges from $1 \%$ to $4 \%$ by weight. The pulp recipe influences the surface quality and the stiffness properties. However, other factors such as the pulp's sustainability and food/drug suitability (FDA) may place constraints on the raw materials used. Dyestuffs, flame retardants, modified starches, and wet-strength resins are additives commonly added for desired end-use effects [33]. One such desired effect important to the molded pulp product industry is waterproofing.

\subsection{Waterproofing}

Waterproof properties are often required in the packaging industry, especially when dealing with food products and beverages. Molded pulp products' mechanical performance changes with respect to the humidity level of their environment, due to the hygroscopic nature of the paper fibers. This phenomenon could jeopardize the structural integrity and storage life of the product.

After the Chinese ban on the use of Styrofoam containers, molded pulp was seen as a viable alternative, but waterproof properties had to be controlled in order to use these products in the food sector. Colloidal rosin and wax emulsions are commonly added with papermaking alum to convert hydrophilic fiber into water-repellent products. Fluorocarbon chemicals, in combination with cationic retention aids, can be added to impart repellency to low surface tension oil and greasy liquids [33].

Table 1 summarizes some of the research efforts that have been made to develop waterproof biodegradable materials, in order to replace the petro-chemical based foam. They are classified by the base material and by the adopted additives.

Table 1: Examples of waterproofing of molded pulp products

\begin{tabular}{llll}
\hline Base material & Additives & References \\
\hline Recycled paper pulp & Diatomite and bentonite, pore structures with good adsorption performance & {$[51]$} & \\
\hline Softwood pulp & $\begin{array}{l}\text { Low molecular weight and highly cationic coagulant followed by a high molecular } \\
\text { weight anionic flocculent. Optimal degrees of grease-proofing and water proofing }\end{array}$ & {$[17]$} \\
\hline $\begin{array}{llll}\text { Unbleached } \quad \text { Kraft } \\
\text { pulp }\end{array}$ & $\begin{array}{l}\text { Palm oil from empty fruit bunch (EFB) and AKD (alkyl ketene dimer). The addition } \\
\text { of EFB provided a higher water contact angle, that gave better water resistance } \\
\text { Old newspapers }\end{array}$ & properties & {$[53]$} \\
\hline
\end{tabular}

\subsection{Alternative pulp materials}


Non-conventional pulp materials have also been explored, and innovative materials such as coconut husk and natural latex have been tested on a laboratory scale. Waranyou [6] produced molded pulp containers made by sugarcane bagasse and binders. Li et al. [54] studied the optimum technology conditions to mix paper pulp with blast furnace slag fiber, an industrial solid waste generated in the process of iron ore. The results showed that products made by compression molding with up to $60 \%$ of blast furnace slag fiber in the mixture met the need of common molded pulp products. Utilizing this knowledge, the environmental impact of the blast furnace slag could be reduced.

Partial combination with more environmentally friendly materials has also been considered. Method company ${ }^{\odot}$ [55], which sells personal and home-care products, with a cradle to cradle certificate, is adding bamboo to the pulping process for their packaging. Bamboo is a fast growing plant, classed as a "rapidly renewable" resource; it doesn't require pesticides, uses little water, and pulls carbon dioxide out of the air faster than other plants [3], [56].

It is clear that once the fundamentals of the production techniques have been fully understood, alternative pulp material will lead to many diverse properties and applications. 


\section{Mechanical properties}

The utilization of molded pulp requires an understanding of the basic mechanical properties. Properties such as tensile strength, compressive strength, bending stiffness, etc. play an important role in the assessment of the strength of the product. However, the relevance of the specific properties and the conditions in which they are tested, often needs to be based on the application. Scientific papers often seek to generalize findings and are therefore of limited use in determining technical feasibility for a specific application.

Paper is a bio-based material and its properties are substantially affected by fiber length, environmental factors such as relative humidity and temperature, and structural properties caused by the drying rate. Therefore, precise engineering equations for the design of paperbased structures cannot be easily derived and design rules and experimentation are usually tailored to the specific application addressed. In the case of products for packaging, the properties typically of interest are the tensile and compressive strength for stacking and the variation in these values due to environmental conditions. The inter-fiber bonding involves hydrogen bonding, so molded pulp is very responsive to the addition of moisture with large strength losses occurring at a high humidity [50].

Molded pulp products are often compared with products of the competing packaging material, polystyrene. The comparison is made by measuring the cushioning effect, the energy absorption, and the impact load carrying capacity [57]. Scientific efforts have been made in order to match the values achieved by the polystyrene products, thus offering a more sustainable alternative. An exact definition of the mechanical properties of molded pulp is not possible, as the mechanical behavior of each sample depends on its size, particular geometry, and wall thickness. The lack of control over dimensional tolerances in the manufacturing of cushioning products has led to considerable variation in material strength and characteristics [58].

\subsection{Stress-strain relationship}

The stress-strain relationship is described by Young's modulus, which is a property of particular interest for composite structures, such as molded pulp. This is more direct than the measured yield strength, which depends on the failure mechanism, which is often driven by the size and orientation of the largest defect in the test volume [59].

$\mathrm{Ji}$ et al. [60] employed a scanning electron microscope (SEM) to study the micro-scale mechanical behavior of molded pulp. The experimental results showed that the material was not only elastic-plastic, but it also has viscous, or emplastic, characteristics. The strain distribution showed irregular characteristics due to the presence of voids, impurities, and the random orientation of fiber fractions. The authors later published research work investigating the stress-strain relationship of molded pulp material under specific conditions. Short span compressive experiments were carried out and the stress-strain curve was then fitted. With the increase of strain rate, the material responded with increased ultimate strength, but maintained the same elastic modulus. The stress also decreased after the sample was unloaded; thus, exhibiting the so-called stress relaxation behavior. These results confirmed that a non-linear emplastic stress-strain model can best describe the behavior of molded pulp [61]. The empirical model employed in this study was: 


$$
\sigma=G\left(\frac{\rho}{\rho_{0}}, \varepsilon\right) M(\varepsilon, \dot{\varepsilon}) f(\varepsilon)
$$

$G\left(\frac{\rho}{\rho_{0}}, \varepsilon\right)$ and $M(\varepsilon, \dot{\varepsilon})$ take into account the effect of density and strain rate on stress respectively. $f(\varepsilon)$ is a dimensionless function of the compressive strain and it reflects the buckling of the structure. $\rho_{0}$ is the reference density. The undetermined coefficients of the function were fitted using load-compressive experimental data.

Figure 8 and Figure 9 show the stress and strain curves for molded pulp in comparison with oriented paper board material. Data were collected from different sources [58], [61], [62]. Molded pulp has been compared with an oriented paper board material, because it has a similar density, but it differs in the way it is manufactured. Like paper, the oriented paper board material shows orthotropic behavior.

Figure 8 shows the tensile stress as a function of extension for molded pulp and paper board along both machine-direction (MD) (the direction the paper flows in production) and crossdirection (CD) (across the width of the paper). Table 2 summarizes the different methodologies and parameter settings, such as the rate at which the tensile test was carried out and the type of specimen used.

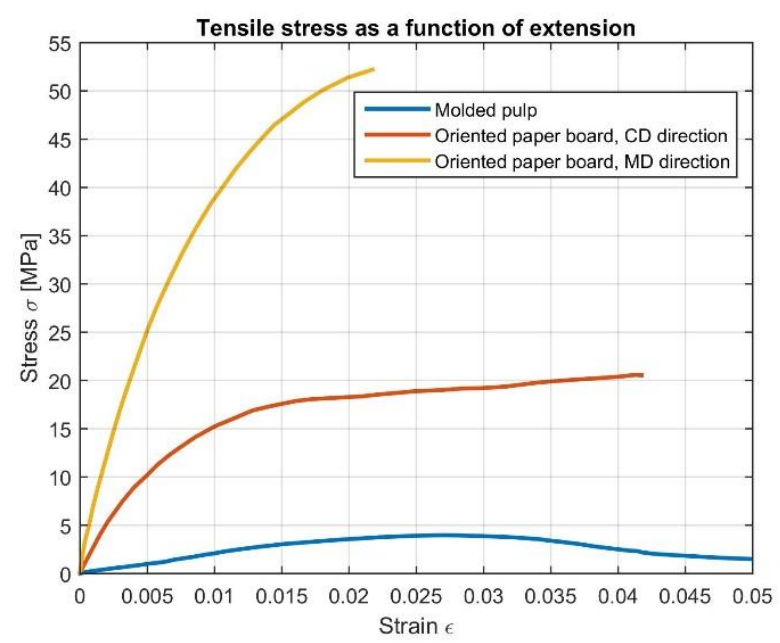

Figure 8: Tensile stress as a function of extension, comparison between molded pulp and paper board (CD: cross-direction; MD: machine-direction)

Table 2: Figure 8 parameter settings

\begin{tabular}{|c|c|c|c|c|}
\hline Color & Rate & Specimen & $\begin{array}{l}\text { Density } \\
{\left[\mathrm{kg} / \mathrm{m}^{3}\right]}\end{array}$ & Reference \\
\hline Blue & $0,00167 \mathrm{~s}^{-1}$ & 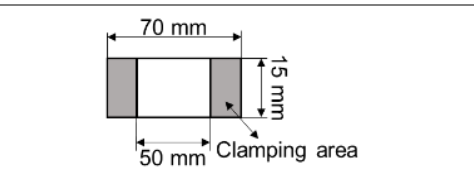 & 350 & {$[58]$} \\
\hline $\begin{array}{l}\text { Orange, CD direction } \\
\text { Yellow, MD direction }\end{array}$ & & $\begin{array}{l}\text { Oriented paper board formed in } \\
\text { a dynamic sheet former } \\
\text { using unbleached chemical pulp }\end{array}$ & 590 & [61] \\
\hline
\end{tabular}


Figure 9 shows the compression stress as a function of compression strain. The comparison between molded pulp and paper board could not be made in the same graph because the strain of the paper board material is two orders of magnitude smaller. Table 3 lists the parameter settings.
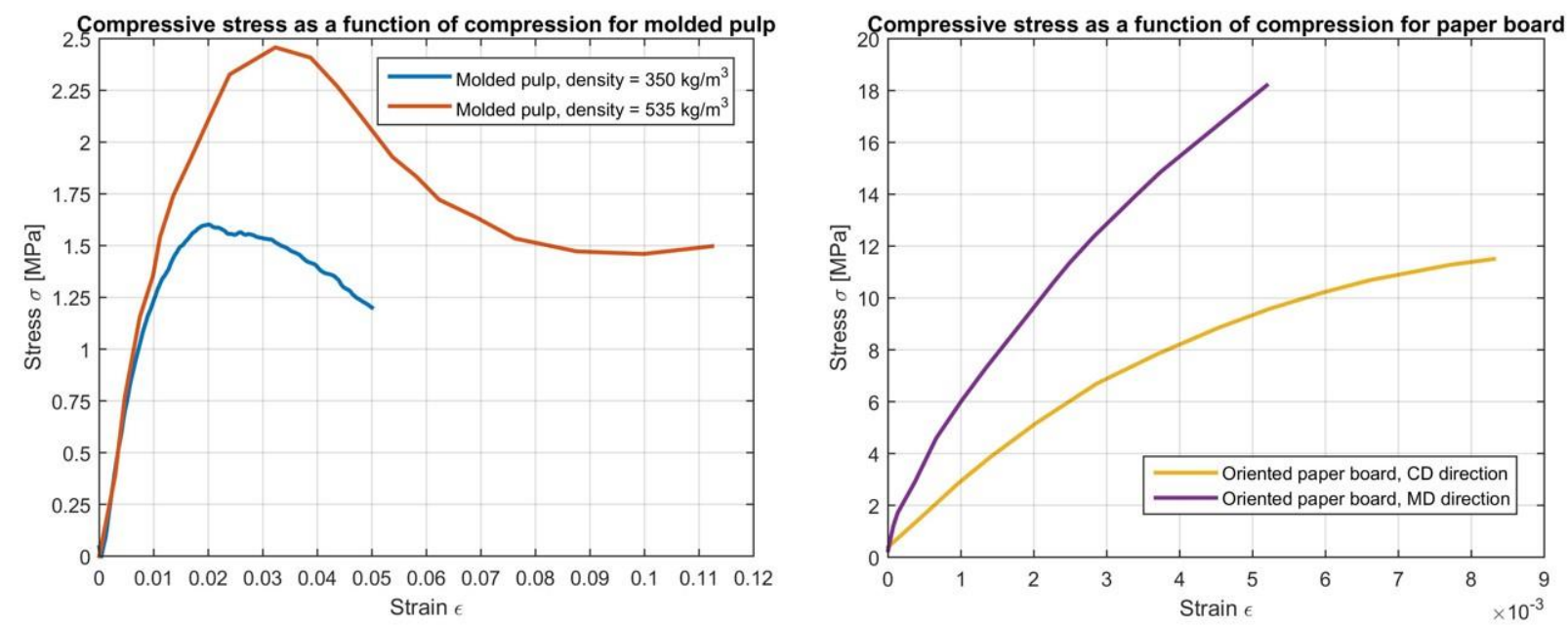

Figure 9: Compression stress as a function of compression for molded pulp (left) and paper board (right) (CD: cross-direction; MD: machine-direction)

Table 3: Figure 9 parameter settings

\begin{tabular}{|c|c|c|c|c|c|}
\hline Color & Test & Rate & Specimen & $\begin{array}{l}\text { Density } \\
{[\mathrm{kg} / \mathrm{m} 3]}\end{array}$ & Reference \\
\hline Blue & $\begin{array}{lr}\text { Short } & \text { span } \\
\text { compression } & \text { test } \\
\text { TAPPI } \quad \text { standard } \\
\text { T826 }\end{array}$ & $0,00833 \mathrm{~s}-1$ & 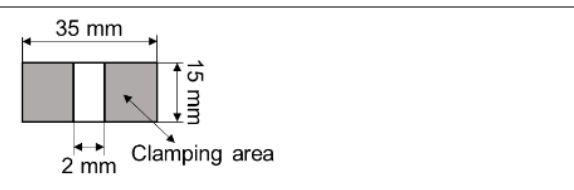 & 350 & {$[58]$} \\
\hline Orange & & & 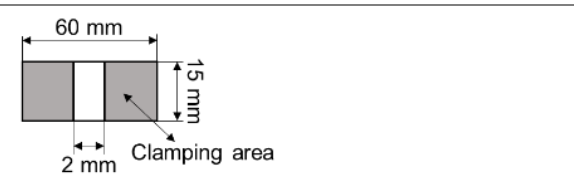 & 535,2 & {$[61]$} \\
\hline $\begin{array}{ll}\text { Yellow, } & \text { CD } \\
\text { direction } & \\
\text { Purple, } & \text { MD } \\
\text { direction } & \end{array}$ & Compression test & & 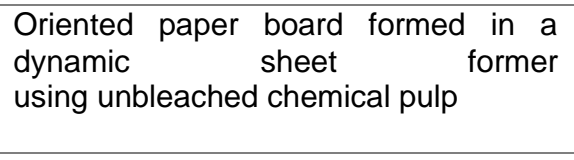 & 590 & [62] \\
\hline
\end{tabular}

The comparison made clear that the tensile strength as a function of the extension of molded pulp is analogous to the paperboard sample. The trend is different, if the same comparison is made with a compression test: the paperboard sample has a tensile strength which is ten times larger than the molded pulp specimen. This is probably due to the different manufacturing process by which the two samples have been produced. The fiber orientation is not controlled in the manufacturing of molded pulp while they assume a defined orientation in the paperboard (i.e. MD and CD). The random orientation of molded pulp fibers generate a lower tensile strength in tension and even lower in compression. Voids and impurities lead to a substantial decrease in mechanical strength and hence samples fail at lower levels of applied load. 


\subsection{Cushioning properties}

For packaging materials, the characteristic most often investigated is the cushioning property. Cushion curves are normally used to show the dynamic shock absorption ability of a cushioning material. The most common method used to determine the shock attenuation is described by the standard ASTM D1596, Standard Test Method for Shock Absorbing Characteristics of Package Cushioning Materials [63]. The transmitted deceleration is plotted against the static loading (product weight per unit area), for a specific material type, thickness and drop height. Cushion curves are used to select the best combination of given materials that would be needed to protect a product with a particular fragility.

The ability to absorb shock depends on several geometric factors, but it also depends on the use of additives [64]. For instance, mixing the pulp with plastic microspheres and starch powder improves the shock absorbing properties [65], but this would make the product harder to recycle. Indeed, following the laws that prohibit the ongoing use of expanded polystyrene, cushion curves were used to compare molded pulp with the plastic rival. Sek et al. [63] concluded no significant difference between the two materials.

Simulations by means of finite elements on the buffer and cushioning performance in a dropping test can be found in [66]-[68]. Results showed good accordance with real tests and the cushioning property of the specimen. Simulations could thus give guidance for designing molded pulp products for specific applications. It is also worth mentioning that other methods have been proposed to study the cushioning properties of molded pulp. One approach enables the determination of the cushion curves from a small number of experimental data points [63]. While another method uses a modified theory for the calculation of the stress from a compression test [69].

\subsection{Degradation}

An important aspect to be considered when dealing with packaging products is the ability to maintain constant stacking strength over time and changes in the environmental conditions. Several processes exist that can contribute to the degradation of molded pulp material, such as photo degradation, thermal degradation, and biodegradation. Ou et al. [70] conducted a study to observe the variation of the mechanical properties of molded pulp containers after prolonged UV irradiation. The tests showed a reduction in the degree of polymerization by $50 \%$, a decrease in weight of $10 \%$ to $16 \%$, and a decrease in the tensile strength of $10 \%$ to $30 \%$.

Another important factor that can cause degradation is a change of the ambient relative humidity during storage. Moisture-induced effects on the stacking strength of molded-fiber packaging were studied by Sørensen et al. [71]. The authors observed that the compression creep behavior resembled that of paper material, which was accelerated by humidity cycling (compared to constant conditions). The effect of temperature variation was also examined by transferring the molded tray from cold storage to ambient conditions. It was concluded that condensation could induce a large initial creep deformation. Compressive failures may also occur during the use of molded pulp products. The failures are often due to buckling, and they develop from internal faults, such as impurities and voids. The random orientation 
of paper-pulp fibers makes it difficult to predict and determine the type and the location of the yielding. 


\section{Environmental sustainability}

When discussing the environmental sustainability of molded pulp products, it is important to realize that they are part of a bigger product life cycle (Figure 10). This life cycle forms the basis for assessing the environmental sustainability of a product. It includes the production of the molded pulp products, sourcing of raw materials, and use and disposal. Many aspects of this life cycle can be relevant for the environmental impact; for instance, whether virgin or recycled fibers are used and if mechanical or chemical pulping is applied. Life Cycle Assessment (LCA) is a tool to analyze the environmental impact of a product throughout its entire lifecycle. This chapter analyzes the potential environmental impacts of molded pulp products by analyzing existing research in the form of LCA studies.

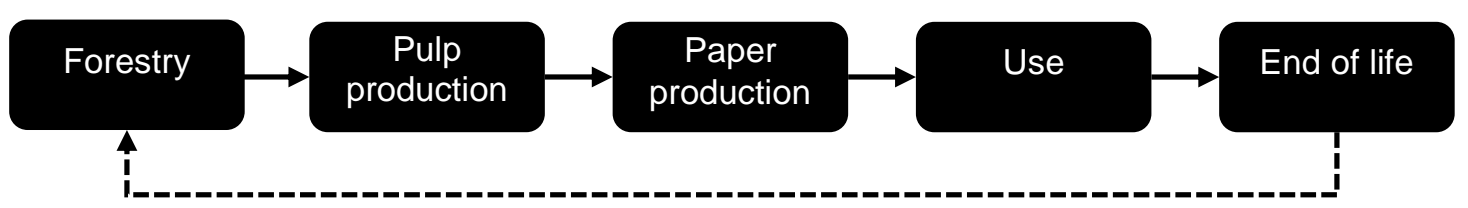

Figure 10: Life cycle stages of molded pulp

\subsection{Available literature}

Existing LCA studies on molded pulp products were collected and compared, showing a wide range of purposes and scopes. The eleven LCA studies that were investigated comprised of one study on wood pulp [72], three studies on wood pulp [73]-[75], four studies on paper [76]-[79], two studies on molded pulp products [80], [81], and one study on waste paper management [82]. This is not expected to be a full list of LCA studies on wood based paper pulp, but it is nevertheless expected to provide decent insight into the life cycle.

Six of the eleven studies aimed to identify hotspots in the life cycle under study, while the other five were comparisons between different (variations of) products. The number of impact categories that were included, capturing various environmental effects, also differed. They ranged from one [82] to seventeen [76]. As more impact categories are included, the picture of the potential environmental impact becomes clearer. Furthermore, the studies also covered different geographies, wood species, and pulping methods. Some studies investigated virgin wood fibers coming directly from the forest, while other studies investigated recycled fibers from various sources.

In addition, the studies covered different life cycle stages. Table 4 illustrates the life cycle stages covered by the studies. The use phase is excluded here, since none of the studies included it. The various results of these studies, plus some other considerations, are discussed per life cycle stage in the rest of this chapter. 


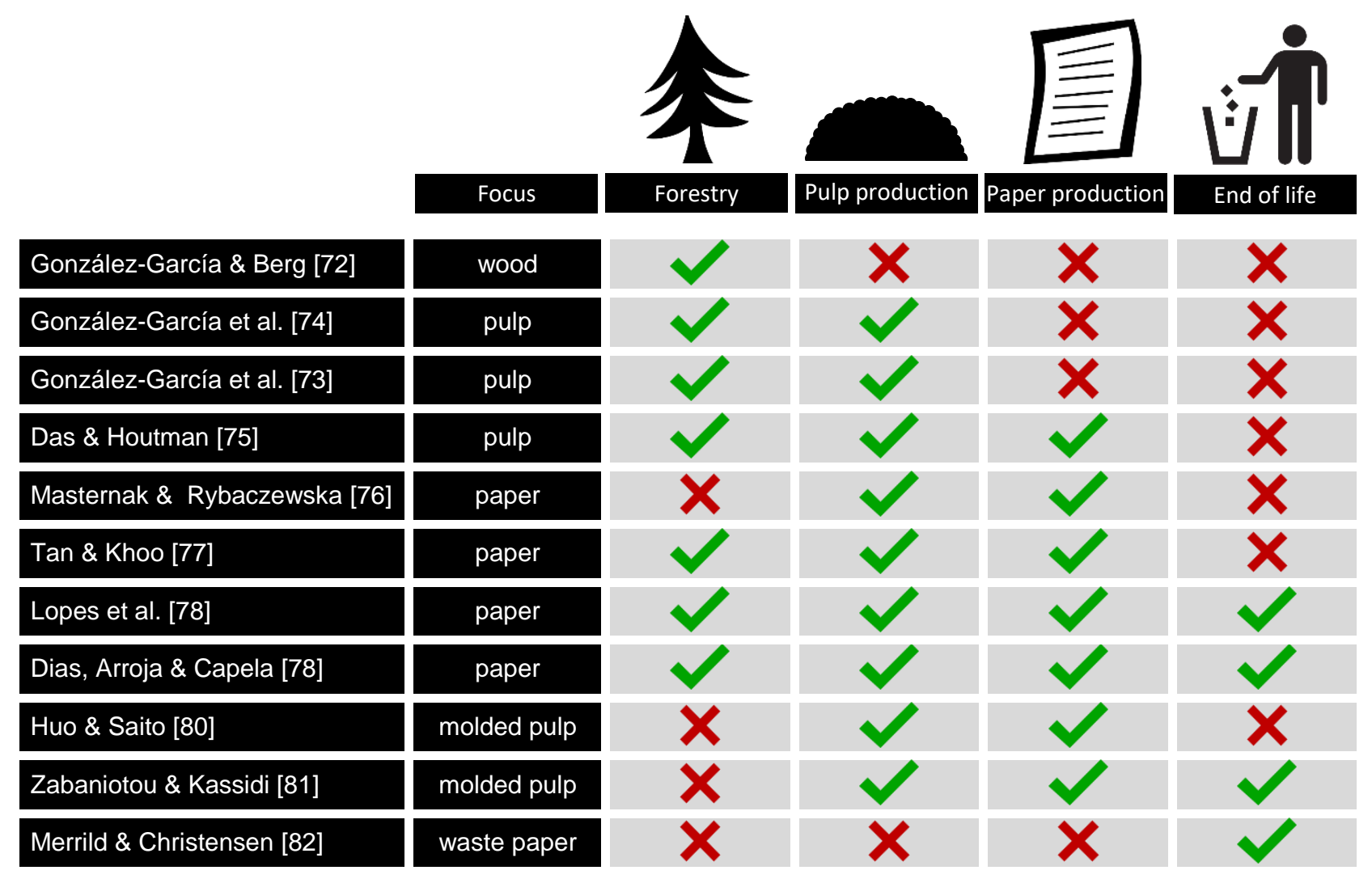

\subsection{Environmental impact of the life cycle stages}

Regarding raw materials, molded pulp products can be made from virgin or recycled wood fibers, using the same production process. An advantage of using recycled fibers is that it reduces the number of trees that are needed and therefore the pressure on forests. In addition, the required energy consumption for producing one ton of recycled fiber pulp is $27 \%$ lower than that for virgin fiber pulp [83]. However, fiber recycling does require the use of various chemicals such as colophony, paraffin emulsion, sizing wax resin, and bauxite.

The LCA that is focused on pulpwood [72] finds that the type of wood, machinery, and fuel influence the environmental impact of the forestry stage. However, the six analyzed LCAs that covered forestry as well as other stages agree that forestry is not a big contributor to the environmental impact of pulp and paper products, regardless of the wood, machinery, or fuel that is used.

Only one of the LCAs compared the use of virgin and recycled fibers [76]. This study only investigates the pulp and paper production stages, reasoning that other studies have shown that the forestry and end of life stages do not have relevant contributions. The results show that the production of one ton of tissue paper from recycled paper has a lower environmental impact than when using virgin fibers. This study also states that using recycled paper to produce tissue paper is a good idea in general, because tissue paper is the final use of paper fibers. This is because the fibers cannot be recovered for recycling after use. 
The quality of the fibers is affected in a negative way every time they are recycled. How many times a fiber can be recycled depends on the wood species, the pulping process, and the way the fiber is used in a product. As a rule of thumb, the fibers can be recycled five to seven times [83].

Regarding the pulp production stage, all the analyzed LCAs that cover either the pulp or paper production stages or both, agree that these two steps have the highest environmental impact in the life cycle. The LCA by Das and Houtman [75] compared the environmental impact of both the mechanical and Kraft chemical pulping process. The study showed that mechanical pulping has a significantly higher impact on global warming. Kraft chemical pulping was found to have a significantly higher impact on acidification. The impacts on the other categories showed limited distinction.

Regarding the paper production, the molding of the pulp into a paper product includes a drying process, which can require a high amount of energy. This is independent of the type of pulping process that is used. The LCA by Huo and Saito [80] shows that this drying process is an important contributor to the overall environmental impact of molded pulp products. The precise environmental impact depends on the heat source that is used; for instance, steam showed lower impact results than heated air.

Regarding the end of life, there are several disposal options for molded pulp products. One option is recycling into other paper products. In order to achieve this, the products have to be collected and processed. The processing includes pulping, screening, refining, washing, drying, and finishing [78]. As stated before, this has the benefit that the energy consumption for creating recycled pulp is lower than that for virgin pulp [83]. The LCA by Merrild and Christensen [82] states that recycling can be better than incineration with energy recovery from an environmental point of view. However, this depends on the specific technologies being used.

Biodegrading is another possibility for paper products depending on the used additives, such as inks and adhesives. If successful, biodegrading can provide a valuable by-product in the form of compost [77], [78].

Another option is landfilling. A specific downside for landfilling paper products is that they can degrade anaerobically in a landfill, causing methane emissions. Since methane is a very powerful greenhouse gas, landfilling can be one of the main contributors to the global warming potential of paper products [77], [78].

Whether molded pulp products are actually a more environmentally sustainable option than other products can only be determined per application. This is because, for example, the amount of material needed and the end of life treatment will differ per application, for both the molded pulp product and the alternative.

The LCA by Zabaniotou and Kassidi [81] compares egg packages made from polystyrene and recycled molded pulp. In this study, the egg packages were landfilled at end of life. The results seem slightly favorable to the recycled molded pulp, but the authors indicate that these results are not accurate and reliable enough due to a lack of available data. It was therefore not possible to provide a final conclusion on which product is more environmentally friendly.

In general, only a limited amount of information about the potential environmental impact of molded pulp products is available. While much can be learned from studies about the 
environmental impact of other paper products, it would be desirable to have more studies about molded pulp products specifically. All investigated LCA studies that include the forestry stage as well as other stages agree that forestry is not a big contributor to the impact. Since the investigated LCA studies agree that pulp and paper production are the most contributing life cycle stages, the focus in future studies should be placed on the activities within these stages. Additionally, special attention needs to be given to the end of life in case landfilling occurs. 


\section{Conclusions}

Environmental, social, and economic concern has resulted in a growing demand for sustainable products and industrial processes. Unfortunately, the field of molded pulp products is under-researched. This work fills this gap and serves as a starting point for designers, engineers, and scientists dealing with the manufacturing of molded pulp products.

This article reviewed the main aspects involved in the molded pulp packaging industry, from the materials selection to the environmental sustainability and disposition. Conclusions and important remarks:

- Design guidelines for the tooling and product's whole process chain are required to make it easier to compare research results, share knowledge, and shorten new molded pulp product development cycles

- The long-term stability and final recovery of the molded pulp material should also be examined [63].

- An industry standard is required for performance testing of molded pulp forming processes and materials. The first step would be to assess the tensile and compressive properties of standardized samples, along with their bending stiffness.

- The applicability of the impulse drying technology for precision molded products is promising and should be further investigated. The potential benefits are great, including a step change in processing time and energy consumption, producing higher quality and performance products. The dewatering mechanism from the impulse drying technique is a complex subject and it is still not fully understood. Therefore, it is important that there be further work in understanding these mechanisms.

- Molded pulp products have the potential to be environmentally sustainable. Whether they are the most environmentally sustainable solution depends on the specific application. Nevertheless, it would be desirable to have more studies about the Life Cycle Assessment (LCA) of molded pulp products specifically.

\section{Acknowledgements}

The authors gratefully acknowledge the support from Innovation Fund Denmark, for funding a consortium between the Department of Mechanical Engineering of the Technical University of Denmark, EcoXpac, Billerudkorsnäs and the Carlsberg Group. 


\section{References}

[1] R. Wever and D. Twede, "The history of molded fiber packaging; a 20th century pulp story," in Proceedings of the 23rd IAPRI symposium on packaging, 2007.

[2] "Molded Pulp Packaging: Trends, Technology \& Developments." [Online]. Available: http://begreenpackaging.com/molded-pulp-packaging/. [Accessed: 25-Jan-2016].

[3] E. Howe, "The Re-invention of Molded Pulp," pp. 1-13, 2010.

[4] "Moulded pulp products - overview and developments," Pap. Technol., vol. 52, no. 3, pp. 28-29, 2011.

[5] R. W. Emery and J. R. Emery, "Review of the pulp molding industry and processes used," Pap. Trade, pp. 29-33, 1966.

[6] S. Waranyou, "Preparation and characterization of moulded pulp container made by hot compression moulding," IPPTA Q. J. Indian Pulp Pap. Tech. Assoc., vol. 26, no. 2, pp. 89-95, 2014.

[7] "About Molded Fiber - International Molded Fiber Association." [Online]. Available: http://imfa.org/i4a/pages/index.cfm?pageid=3283. [Accessed: 14-Dec-2015].

[8] B.-U. Cho, J. Y. Ryu, and B. Fabry, "Optimization of repulping process of unsorted ONP for pulp mold (II) - Pilot trial," J. Korea Tech. Assoc. Pulp Pap. Ind., vol. 39, no. 5, 2007.

[9] F. E. Keyes, "Method of molding pulp articles," US 424,003, 1890.

[10] M. L. Keyes, “Apparatus for making pulp articles," US 740,023, 1903.

[11] M. L. Keyes, "Machine for molding articles from pulp," US 759,616, 1904.

[12] M. Koppelman and S. Cooper, "Packaging for fragile articles," US 1,429,207, 1922.

[13] S. Price and E. C. Sloan, "Package," US 2,217,455, 1940.

[14] Ma Su-chang, Tan Run-hua, and Liu Xue-bin, "Optimization design of molded honeycomb mold based on Pro/Mechanica," in 2010 2nd International Asia Conference on Informatics in Control, Automation and Robotics (CAR 2010), 2010, vol. 3, pp. 40-43.

[15] Tetra Pak, "Sustainability Update," 2015.

[16] Innventia, “Innventia Global Outlook Packaging 2020," 2013.

[17] Y. S. Perng and I. C. Wang, "A parametric investigation on the use of fluorinated greaseproofing chemicals in molded paper products," Taiwan J. For. Sci., vol. 19, no. 2, pp. 103-108, 2004.

[18] CEPI, "The Age of Fibre," 2015.

[19] J. Lehrer, "Reduced to a pulp," Best Practices, pp. 34-36, 2011.

[20] "Paper Water Bottle®." [Online]. Available: http://paperwaterbottle.com/. [Accessed: 21-Mar-2015]. 
[21] "Green Fiber Bottle project - DTU Mechanical Engineering." [Online]. Available: http://www.mek.dtu.dk/english/sections/kp/research/current-projects/green-fiberbottle-project.

[22] E. Brilhuis-Meijer and P. Saxena, "The sustainable future of packaging: A biodegradable paper beer bottle,” B. Abstr. Dtu's Sustain Conf. 2015, 2015.

[23] G. B. Gavazzo, R. Lanouette, and J. L. Valade, "Study of the important variables of a pulp molding process," ATIP. Assoc. Tech. L'Industrie Papet., vol. 57, no. 4, 2003.

[24] J. Bear, Dynamics of Fluids in Porous Media. 1972.

[25] W. B. Campbell, "The physics of water removal," Pulp Pap. Mag. Canada, pp. 103122, 1947.

[26] N. L. Chang, "Dynamic compression of handsheets," Tappi, pp. 93-106, 1978.

[27] C. Zotterman and D. Wahren, "A technique for simulating production quality of highspeed wet press runs," Pap. Trade J., vol. 162, no. 16, pp. 37-38, 1978.

[28] G. Carlsson, Some fundamental aspects of the wet pressing of paper. Royal Institute of Technology, 1983.

[29] M. A. MacGregor, "A description of sheet stratification caused by wet pressing," in Practical Aspects of Pressing and Drying Seminar, 1986, pp. 63-67.

[30] M. A. MacGregor, "Wet pressing research in 1989. An historical perspective, analysis and commentary.," in The 9th Fundamental Research Symposium, Cambridge, 1989, vol. 2, pp. 511-585.

[31] H. Vomhoff and B. Norman, "Model experiments on wet pressing - The influence of felt surface structure," Nord. Pulp Pap. Res. J., vol. 12, no. 1, pp. 54-60, 1997.

[32] M. Goto and K. Eto, "Method for producing pulp molding," WO 01/079609, 2003.

[33] K. L. Yam, Ed., The Wiley Encyclopedia of Packaging Technology. Hoboken, NJ, USA: John Wiley \& Sons, Inc., 2009.

[34] K. Y. P. Martínez, E. A. V. Toso, and R. Morabito, "Production planning in the molded pulp packaging industry," Comput. Ind. Eng., vol. 98, pp. 554-566, Aug. 2016.

[35] K. Søllner, "A system and a method for producing a molded article, such as a bottle," WO2016/055073 A1, 2016.

[36] D. Wahren, "Impulse Drying," in The 47th Executives' Conference, 1983, pp. 54-60.

[37] D. I. Orloff, "Impulse drying of linerboard: Control of delamination," Annu. Meet. - Tech. Sect. Can. Pulp Pap. Assoc. Prepr., no. pt B, pp. 9-25, 1991.

[38] P. Mendes, N. Belgacem, and J. F. Bloch, "Impulse drying technology: The state of the art and the recent advances," Atip. Assoc. Tech. L'industrie Papet., vol. 58, no. 1, pp. 25-34, 2004.

[39] E. Luiten and K. Blok, "Stimulating R\&D of industrial energy-efficient technology. Policy lessons-impulse technology," Energy Policy, vol. 32, no. 9, pp. 1087-1108, Jun. 2004. 
[40] M. F. C. Lucisano, P. Mazzatorta, and D. M. Martinez, "On the mechanism of steam forming during impulse pressing of wet paper webs," Nord. Pulp Pap. Res. J., vol. 16, no. 4, pp. 355-361, 2001.

[41] M. F. C. Lucisano and A. R. Martin, "Visualization of liquid-vapor phase change phenomena in impulse technology," Tappi J., vol. 5, no. 6, pp. 15-21, 2006.

[42] M. F. C. Lucisano and D. M. Martinez, "On the characterization of the delamination process during impulse pressing," Nord. Pulp Pap. Res. J., vol. 16, no. 4, 2001.

[43] M. Didone and G. Tosello, "Potential of impulse drying technology for molded pulp products manufacture," in Progress in Paper Physics Seminar 2016, 2016, pp. 9-15.

[44] S. T. Seana, B. Sanschagrina, B. V Koktab, and D. Maldasb, "Effects of processing variables on the mechanical properties of compression molded polystyrene-wood fiber composites," Die Angew. Makromol. Chemie, vol. 184, no. 3128, pp. 157-166, 1991.

[45] Y. Kumamoto and K. Otani, "Method for producing pulp molded article," US 2001/0040016 A1, 2001.

[46] Y. Kumamoto, S. Otakura, K. Otani, S. Odajima, and T. Tsuura, "Method of Manufacturing Pulp Molded Product," US 6,468,398 B1, 2002.

[47] T. Tsuura and M. Osaki, "Production method and device for fiber molding," US 2004/0041305 A1, 2004.

[48] T. Tsuura, H. Kobayashi, K. Otani, M. Osaki, and S. Odajima, "Method for producing pulp moldings," US 7,067,041 B2.

[49] A. Diener, A. Grundei, and O. Tretzack, "Method for producing moulded articles," US 2015/0114256 A1, 2015.

[50] J. C. F. Walker, "Pulp and paper manufacture," in Primary Wood Processing: Principles and Practice, Springer Netherlands, 2006, pp. 477-534.

[51] X. Shi, X. Wang, W. Wengsheng, X. Heng, and D. Dongxue, "Research on the humidity-controlled performance of fruits and vegetables molded pulp salver," Res. Prog. Pap. Ind. Biorefinery (4th Isetpp), vol. 1-3, pp. 1694-1696, 2010.

[52] Y. J. Sung, H. M. Kim, D. S. Kim, and J. Y. Lee, "Evaluation of Water Resistance Properties of Pulp Mold depending on the Types of Raw Materials and the Additives," J. Korea Tech. Assoc. Pulp Pap. Ind., vol. 47, no. 5, pp. 112-119, Oct. 2015.

[53] D.-S. Kim, Y. J. Sung, C.-H. Kim, and S.-B. Kim, "Changes in the Process Efficiency and Product Properties of Pulp Mold by the Application of Oil Palm EFB," J. Korea Tech. Assoc. Pulp Pap. Ind., vol. 48, no. 1, pp. 67-74, Feb. 2016.

[54] S. Li, G. Sun, and R. Yang, "Preliminary Study on Molded Pulp Products by Using Blast Furnace Slag Fibre," in Proceedings of International Conference on Pulping, Papermaking and Biotechnology, 2008, pp. 132-135.

[55] "method." [Online]. Available: http://methodhome.com/.

[56] "Growing the Future of Bamboo Products." [Online]. Available: https://www.greenbiz.com/news/2009/07/09/growing-future-bamboo-products. 
[57] Z. Wang and C. Peng, "Analysis for impact load carrying capacity and energy absorbing of molded pulp products," Chinese J. Appl. Mech., vol. 30, no. 4, 2013.

[58] S. P. Gurav, A. Bereznitski, A. J. Heidweiller, and P. V Kandachar, "Mechanical properties of paper-pulp packaging," Compos. Sci. Technol. IF - 1.320, vol. 63, pp. 1325-1334, 2003.

[59] H. Nilsson, S. Galland, P. T. Larsson, E. K. Gamstedt, and T. Iversen, "Compression molded wood pulp biocomposites: a study of hemicellulose influence on cellulose supramolecular structure and material properties," Cellulose, vol. 19, no. 3, pp. 751760, Jun. 2012.

[60] H. Ji, H. Wang, and J. Chen, "Mechanical Behaviors of Molded Pulp Material," in SPIE - The International Society for Optical Engineering, 2008, vol. 7375, p. 73756D73756D-5.

[61] H. Ji and H. Wang, "Short Span Compressive Stress-Strain Relation and Model of Molded Pulp Material,” Key Eng. Mater., vol. 450, pp. 202-205, 2010.

[62] L. Carlsson, C. Fellers, and A. De Ruvo, "The mechanism of failure in bending of paperboard," J. Mater. Sci., vol. 15, no. 10, pp. 2636-2642, 1980.

[63] M. A. Sek, M. Minett, V. Rouillard, and B. Bruscella, "A New Method for the Determination of Cushion Curves," Packag. Technol. Sci., vol. 13, pp. 249-255, 2000.

[64] D. G. Eagleton and J. A. Marcondes, "Cushioning Properties of Moulded Pulp," vol. 7 , pp. 65-72, 1994.

[65] T. Noguchi, M. Miyashita, J. Seto, and M. Kawano, "Development of Moulded Pulp Materials for the Packaging of Electronic Equipment," vol. 10, pp. 161-168, 1997.

[66] G. Xin, J. Hongwei, and Z. Haiyou, "Finite Element Simulation of Molded Pulp Pallet in the Dropping Process," Appl. Mech. Mater., vol. 469, pp. 209-212, 2014.

[67] D. W. Geng and W. C. Xu, "Study on Method of Simulating Dynamic Cushioning Performance of Molded Pulp Packaging Pad," Adv. Mater. Res., vol. 174, no. 174, pp. 510-512, Dec. 2010.

[68] Z. Wang, Y. Cai, and Y. Jing, "Molded Pulp Material Structure Parameters on the Performance of the Buffer," Energy Procedia, vol. 17, no. PART B, pp. 1872-1877, 2012.

[69] H. T. Wang, Y. F. Guo, and G. L. Luo, "Mechanical Properties of Molded Pulp Pallet," Appl. Mech. Mater., vol. 121-126, pp. 216-220, 2011.

[70] Y. Ou and Q. Huang, "Study on the Photo Degradation of Pulp Mold Container," Appl. Polym. Sci., vol. 87, pp. 2052-2056, 2003.

[71] G. Sørensen and J. Hoffmann, "Moisture-induced effects on stacking strength of moulded-fibre packaging in varying environmental conditions," Packag. Technol. Sci., vol. 17, no. 5, pp. 257-265, 2004.

[72] S. González-García, S. Berg, G. Feijoo, and M. T. Moreira, "Environmental impacts of forest production and supply of pulpwood: Spanish and Swedish case studies," Int. J. 
Life Cycle Assess., vol. 14, no. 4, pp. 340-353, 2009.

[73] S. González-García, A. Hospido, M. T. Moreira, J. Romero, and G. Feijoo, "Environmental impact assessment of total chlorine free pulp from Eucalyptus globulus in Spain," J. Clean. Prod., vol. 17, no. 11, pp. 1010-1016, 2009.

[74] S. González-García, A. Hospido, R. Agnemo, P. Svensson, E. Selling, M. T. Moreira, and G. Feijoo, "Environmental Life Cycle Assessment of a Swedish Dissolving Pulp Mill Integrated Biorefinery," J. Ind. Ecol., vol. 15, no. 4, pp. 568-583, 2011.

[75] T. K. Das and C. Houtman, "Evaluating chemical-, Mechanical-, and bio-pulping processes and their sustainability characterization using life-cycle assessment," Environ. Prog., vol. 23, no. 4, pp. 347-357, 2004.

[76] A. Masternak-Janus and M. Rybaczewska-Błażejowska, "Life Cycle Analysis of Tissue Paper Manufacturing From Virgin Pulp or Recycled Waste Paper," Manag. Prod. Eng. Rev., vol. 6, no. 3, pp. 47-54, 2015.

[77] R. B. H. Tan and H. H. Khoo, "Life cycle assessment of EPS and CPB inserts: Design considerations and end of life scenarios," J. Environ. Manage., vol. 74, no. 3, pp. 195205, 2005.

[78] E. Lopes, a Dias, L. Arroja, I. Capela, and F. Pereira, "Application of life cycle assessment to the Portuguese pulp and paper industry," J. Clean. Prod., vol. 11, no. 1, pp. 51-59, 2003.

[79] A. C. Dias, L. Arroja, and I. Capela, "Life cycle assessment of printing and writing paper produced in Portugal," Int. J. Life Cycle Assess., vol. 12, no. 7, pp. 521-528, 2007.

[80] B. L. Huo and K. Saito, "Multidimensional Life Cycle Assessment on Various Moulded Pulp Production Systems," Packag. Technol. Sci., vol. 22, pp. 261-273, 2009.

[81] A. Zabaniotou and E. Kassidi, "Life cycle assessment applied to egg packaging made from polystyrene and recycled paper," J. Clean. Prod., vol. 11, no. 5, pp. 549-559, 2003.

[82] H. Merrild, A. Damgaard, and T. H. Christensen, "Life cycle assessment of waste paper management: The importance of technology data and system boundaries in assessing recycling and incineration," Resour. Conserv. Recycl., vol. 52, no. 12, pp. 1391-1398, 2008.

[83] P. Bajpai, Recycling and Deinking of Recovered Paper. London, UK: Elsevier Science, 2014. 